\title{
Effects of Blood Depletion for Psychological State of Illness, Self- Esteem, Physical Symptoms on Life Satisfaction
}

\author{
Kyung-Bae Kim ${ }^{1 *}$ and Sung-Jae Jo ${ }^{2}$

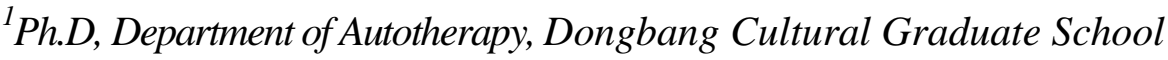 \\ mosu2003@hanmail.net \\ ${ }^{2}$ Professor, Department of Education, Dongbang Cultural Graduate School
}

\begin{abstract}
The purpose of this study is to understand the effects of blood depletion for the psychological state of illness, self-esteem, and physical symptoms on life satisfaction. For this study, a questionnaire survey was conducted from September 5th, 2014 to November 30th, 2014 on subjects in Gangbuk region of Seoul who were undergoing blood depletion treatment. The data analysis of the test subjects was performed by using the SPSS 21.0 and the hypotheses were verified using the structural equation. The following are the results: first, psychological state of illness was observed to have a significant effect on the self-esteem factors after the blood depletion treatment; second, the psychological state of illness was observed to influence satisfaction level after the blood depletion treatment; third, the psychological state of illness was observed to have a significant effect on the factors of physical symptoms after the depletion treatment;fourth, the post-depletion satisfaction level was observed to affect the life satisfaction level; and fifth, it was shown that the post-depletion satisfaction factors played the intermediary role. The analysis results of this study are expected to serve as the basic data for the natural therapy research, as they provide the analysis results of the effects of blood depletion for psychological state of illness, self-esteem, and physical symptoms on life satisfaction.
\end{abstract}

Keywords: Blood Depletion, Psychological State of Illness, Self-Esteem, Physical Symptoms, Life Satisfaction

\section{Introduction}

\subsection{Introduction}

All humans seek to lead a healthy and pleasant life free of any illness. Hippocrates identified the illness to be a natural phenomenon rather than devil's curse. The quality of life was emphasized even back then (B.C.4607-)[1]. Human life is affected by climate changes of the natural world. Especially according to the belief of the inherent ganjiohheng (oriental studies based on the Chinese sexagenarian cycle and five primary elements: wood, fire, earth, metal, and water), leaning too much towards or lacking in any one of the five elements will lead to disharmony in the organs, resulting in illness [2].

$\ulcorner$ Somun(素問)•Eumyangeumsangdaeron (陰陽應象大論) $」$ states that the cure for illness must be found from the yin and yang, which is the rule of the natural world(治病必求於本). In the Eastern medicine, imbalance in the yin and yang of the natural world is considered to be the cause of illness [3.4].

In the Eastern medicine, illness refers to the state of imbalance of the energy of the yin and yang inside the body and the treatment refers to the act of restoring the balance [5].

In the Western medicine, the illness is believed to be caused by the blood flow problems due to the contraction of sympathetic nerve (陽) by adrenalin, drop in the body temperature and immunity, and the creation of ulhyeol(攀血), or congestion of blood, 
produced by the excessive expansion of blood vessels by the acetylcholine from the parasympathetic nerve (陰). This shows similarity in the theories about the causes of illness in the Eastern and Western medicines.

However, people live with the fear of having illnesses. Especially in the case of cancer, the pain from the fear of cancer is unbearable for most people. Thus, the ancient sages have stated that our minds need to be cured before illnesses (欲其之治病先其之治心).

When cancer progresses, inadequate blood flow leads to the hardening of the blood vessels and rotting of the surrounding regions. This phenomenon of uhyeol (or blood stasis), is most alerting in the Eastern medicine [7]. In addition, the illnesses that arise from the blood stasis can lead to inactive social and economic activities. Accordingly, this study seeks to understand the effects of blood depletion for psychological state of illness, self-esteem, and physical symptoms on life satisfaction.

\subsection{Problem Statement}

The problems of the study are as follows.

1) What are the post-depletion effects of psychological state of illness in relation to the self-esteem factors?

2) What are the post-depletion effects of psychological state of illness in relation to the satisfaction factors?

3) What are the post-depletion effects of psychological state of illness in relation to the physical symptom factors?

4) What are the effects of post-depletion satisfaction in relation to the life satisfaction?

5) What intermediary roles do the post-depletion satisfaction factors play on the effects that psychological state of illness has on the life satisfaction?

\section{Theoretical Background}

\subsection{The Need for Research}

In「Somun•Janggibupsiron(藏氣法時論)」Janggyebin (張介賓) states that “Jokgwolumgangyung(足厥陰肝經) is eulmok(乙木), and joksoeumdangyeong (足少陰膽經) is gapmok (甲木), meaning that liver and gallbladder are in an exteriorinterior relationship and can be cured by using similar treatment method. Gab (甲， dominant) is yangmok (陽木) and the eul (乙, submissive) is eumok (陰木), which correspond to liver and gallbladder. It also indicates that hurriedness could irritate and damage the liver, which is an organ equivalent to the rank of General, hence it must be eased with sweetness. Finally it states that the treatments listed in other books are all identical(厥陰肝,乙木也,少陽膽,甲木也.二藏表里,故治同,甲爲陽木,乙爲陰木,皆東方

之于,內応肝膽. 則年月日時无不皆然, 他放皆) [8,9].

The organs and illnesses discussed in this literature are caused by ganjiohheng(干支五行) of people and the four seasons, and they could be cured by achieving harmony in the yin and yang. Due to the climate changes, people are living under the fear of gilhyunghwabok(吉凶禍福, fortunes) and illnesses. Thus, research on the natural therapy of illnesses began for healthier lives without worries.

Existing previous studies can be classified as studies on blood depletion and illness, which are based on the study of numerology. Firstly, the blood depletion technique from the previous studies stated that removing the eochae (瘀滯), or the congestion of the blood vessel, and making the smooth flow of aeremia will balance the yin and yang and cure the illness [10].

Secondly, the 『Jukcheonsucheonmi (滴天髓闡微)』 on numerological illness stated that " those with disorderly vitality frequently have many life-long illnesses and the 
harmony in the five elements leads to a life without calamity (血氣亂者, 生平多疾. 五行和者, 一世无災).[11], Dr. Chang-geun Jung stated that "each organ has correlation to the excess (太過) and insufficiency (不及) of ganjioheng, the incongruity of the original and annual states, the annual mix by spirit, and the surgical sites" [12]. This indicates that illness can be predicted by the correlation between ohjangyukbu (internal organs), eumyangohheng (yin yang and five elements), heosil (weakness and strength), and hanyeol (heat and cold). MOre specifically, this means that illness is created by disharmony, excess, and insufficiency in the five elements, as well ashanyeol in the body [13]. Therefore, illnesses can be prevented by understanding the indicators of illnesses before they aggravate by analyzing numerological illnesses and employing blood depletion treatment. Accordingly, harmonizing the excessive or insufficient elements could free people from illnesses. The previous studies extremely lack in studies on the numerological illnesses and blood depletion in relation to life, as most of the studies were on blood depletion, illness, and numerological illness [2-13]. Therefore, there is a need to improve and supplement the problems from previous studies.

\section{Study Methods}

\subsection{Study Subjects}

For this study, a questionnaire survey was conducted on the people, who were receiving blood depletion treatments in Gangbuk region of Seoul from 09-05-2014 to 1130-2015. The basis of the calculation was verified according to Cohen's sampling equation.

\subsection{Research Tools}

\subsubsection{Self-Esteem and Life Satisfaction after Illness-Preventive Blood Depletion}

For this study, 20 questions on psychological state of illness, 20 questions on physical symptoms, 20 questions on blood depletion satisfaction, 10 questions on self-esteem, and 5 questions on life satisfaction were selected, modified, and revised from the questionnaires of Chong-sun Park [22], Yung-ja Lee[1]1, 10 self-esteem questions, and questions of Wan-seok Kim and Yeong-jin Kim[5]. High average corresponds to high life satisfaction [14]

\subsubsection{Data Processing and Analysis}

The collected data were analyzed by using SPSS 21.0 and structural equation, in terms of frequency, exploratory factor, and confirmatory factor. Amos 21.0 was used to propose the figure for the analysis results of correlation and the verification of credibility. Furthermore, the path coefficients were proposed by using the structural equation, in order to verify the study hypotheses [15].

\section{Results of Analysis}

\subsection{Effects of Psychological State of Illness on Self-Esteem, Satisfaction and Physical Symptoms After Blood Depletion Treatment}

The paths for psychological state of illness, self-esteem, satisfaction, and physical symptom are as shown in Table 1. The analysis about the effects of psychological state of illness on the self-esteem factors indicated a significant influence $(p<.05>)$, with the value of $\beta=.955$. When analyzing the psychological state illness in relation to the satisfaction factors after blood depletion, a significant influence $(\mathrm{p}<.001>)$ was observed with the value of $\beta \beta=.897$. When analyzing the effect of psychological state illness on the 
physical symptom factors, a significantly negative influence $(\mathrm{p}<.001>)$ was observed, with the value of be .727 . Such results confirm the H1, H2, and $\mathrm{H} 3$, which hypothesized the post-depletion effects of psychological state of illness on the self-esteem factor, satisfaction factor, and physical symptom factor, respectively.

Table 1. Paths for the Psychological State of IIIness, Self-esteem, Satisfaction and Physical Symptom

\begin{tabular}{|c|c|c|c|c|c|c|c|}
\hline Path & & & $\begin{array}{l}\text { Standard } \\
\text { Coefficient }\end{array}$ & $\begin{array}{l}\text { Non- } \\
\text { Standard } \\
\text { Coefficient }\end{array}$ & S.E. & C.R. & $P$ \\
\hline $\begin{array}{l}\text { Self-Esteem } \\
\text { Factors }\end{array}$ & $<-$ & $\begin{array}{l}\text { Psychological } \\
\text { State of Illness }\end{array}$ & .955 & .193 & .084 & $2.304 *$ & .021 \\
\hline $\begin{array}{l}\text { Post-Depletion } \\
\text { Satisfaction }\end{array}$ & $<-$ & $\begin{array}{l}\text { Psychological } \\
\text { State of Illness }\end{array}$ & .897 & .680 & .056 & $12.228 * * *$. & .000 \\
\hline $\begin{array}{l}\text { Physical } \\
\text { Symptom } \\
\text { Factors }\end{array}$ & $<-$ & $\begin{array}{l}\text { Psychological } \\
\text { State of Illness }\end{array}$ & -.727 & -.655 & .073 & $-8.917 * * *$ & .000 \\
\hline
\end{tabular}

\section{2. Confirmatory Factors of Each Factor}

The confirmatory factor of each component was analyzed through the analysis of exploratory factors and credibility factors.

Table 2. Fitness Index of Confirmatory Factors

\begin{tabular}{|c|c|c|c|c|c|c|c|c|}
\hline$\chi^{2}$ & RMSEA & $\mathrm{Q} V \mathrm{a}$ & NFI & CFI & GFI & AGFI & TLI & Delta 2 \\
\hline 387.92 & .011 & 3.55 & .902 & .924 & .953 & .916 & .926 & .901 \\
\hline
\end{tabular}

The fitness index of confirmatory factors is shown in Table 2 . Analyzing the fitness of the structural equation to the hypotheses, the resulting values of $\chi^{2} 387,92, \mathrm{p}, 000, \mathrm{Q} 3.55$, RMSEA. 011, NFI, 902, CFI, 924, GFI, 953, AGFI, 916, TLI, 926, Delta2, 901 verified the structural model of the as well as the fitness of the path-coefficients. The soundness of the hypotheses was confirmed to be satisfactory.

\section{3. Verification of Hypotheses}

Overall structural model of the $x^{2}$ model was analyzed. The result of the fitness index analysis from the structural analysis is as shown in Table 3. The fitness of the model was verified as shown in the chart.

Table 3. Comparison of Fitness of the Study Model

\begin{tabular}{l|llll}
\hline \multicolumn{2}{l}{ Fitness Index } & Study Model & $\begin{array}{l}\text { Correction } \\
\text { Model }\end{array}$ & Acceptance Level \\
\hline & $\chi^{2}{ }^{2}$ Value $(\mathrm{p})$ & $307.74(\mathrm{p}<.001)$ & $\begin{array}{l}253.84 \\
(\mathrm{p}<.001)\end{array}$ & $\begin{array}{l}\text { Comparing } \\
\text { calculated value of } \chi^{2} \\
\text { with the critical value }\end{array}$ \\
Absolute & $\mathrm{Q}$ & 2.66 & 2.07 & \\
Fitness & GFI & .760 & .926 & Over .90 outstanding \\
Index & RMR & .059 & .057 & Below .05 outstanding \\
& RMSEA & .122 & .018 & $\begin{array}{l}\text { Below .10 Fit } \\
\text { Below .05 Very Fit } \\
\end{array}$ \\
\cline { 2 - 5 } & AGFI & .761 & .900 & Over .90 outstanding \\
\hline
\end{tabular}




\begin{tabular}{l|llll}
\hline Relative & TLI & .857 & .903 & Over .90 outstanding \\
Fitness & NFI & .824 & .953 & Over .90 outstanding \\
Index & CFI & .880 & .909 & Over .90 outstanding \\
& IFI & .882 & .911 & Over .90 outstanding \\
\hline
\end{tabular}

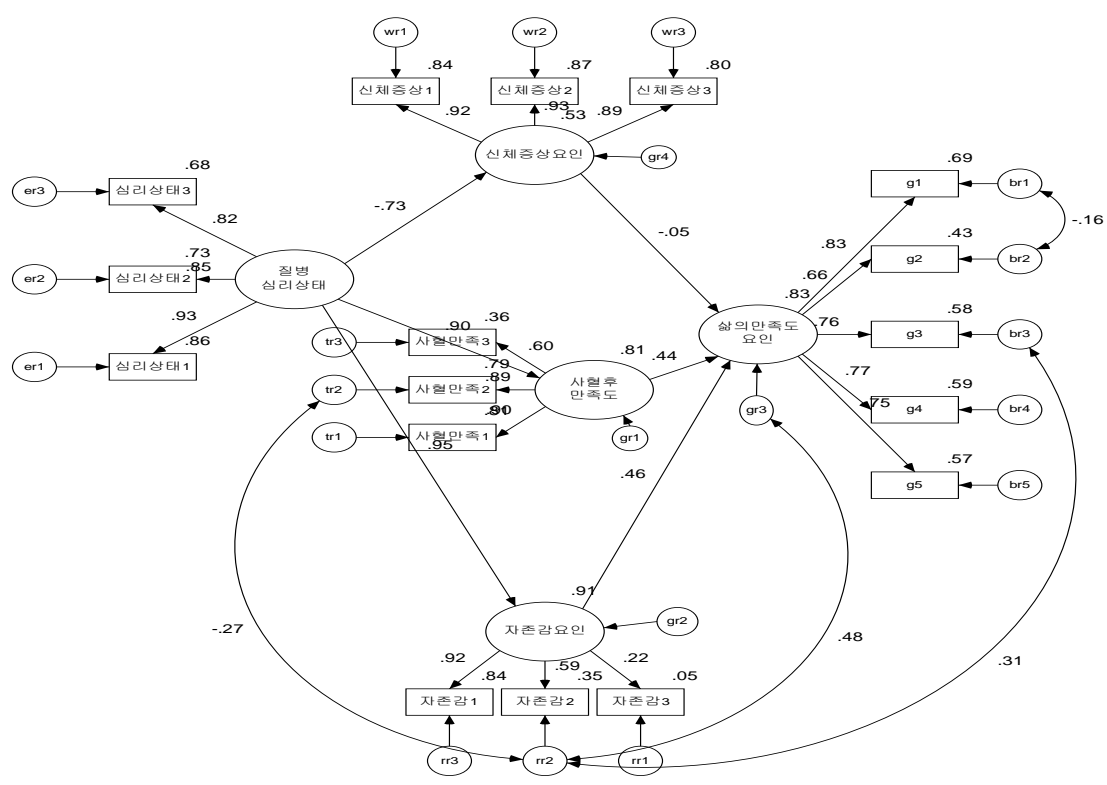

Figure 1. Result of the Revised Path Model

\subsection{Correlation Analysis and Distinction Analysis}

Table 4 shows the correlation analysis and distinction analysis of the variables in this study. In order to understand the relationship and the direction, the correlation with the criterion of each unit with proved single level was analyzed. A significant positive correlation was observed in most variables.

\section{Table 4. Correlation Analysis and Distinction Analysis}

\begin{tabular}{|c|c|c|c|c|c|}
\hline & $\begin{array}{l}\text { Psycholog } \\
\text { State } \\
\text { Illness }\end{array}$ & $\begin{array}{l}\text { cal Physical } \\
\text { ofSymptoms }\end{array}$ & $\begin{array}{l}\text { Depletion } \\
\text { Satisfaction }\end{array}$ & Self-Esteem & $\begin{array}{l}\text { Life } \\
\text { Satisfaction }\end{array}$ \\
\hline Psychological State & 1 & & & & \\
\hline Physical Symptoms & $-.651(* *)$ & 1 & & & \\
\hline Depletion Satisfaction & $.770(* *)$ & $-.606(* *)$ & 1 & & \\
\hline Self-Esteem & $.800(* *)$ & $-.639(* *)$ & $.794(* *)$ & 1 & \\
\hline Life Satisfaction & $.736(* *)$ & $-.571(* *)$ & $.788(* *)$ & $.848(* *)$ & 1 \\
\hline
\end{tabular}

\subsection{Effect of Post-Depletion Satisfaction on Life Satisfaction}

Table 5. Paths of the Post-Depletion Satisfaction and Life Satisfaction

\begin{tabular}{l|lll|l|l|l|l}
\hline Path & \multicolumn{3}{c}{$\begin{array}{l}\text { Standard } \\
\text { Coefficient }\end{array}$} & $\begin{array}{l}\text { Non- } \\
\text { Standard } \\
\text { Coefficient }\end{array}$ & S.E. & C.R. & P \\
$\begin{array}{l}\text { Life } \\
\begin{array}{l}\text { Satisfaction } \\
\text { Factor }\end{array}\end{array}$ & $<-$ & $\begin{array}{l}\text { Physical } \\
\text { Symptom } \\
\text { Life }\end{array}$ & -.052 & -.049 & .069 & -.707 & .480 \\
\hline Factors & $<-$ & Self-Esteem & .462 & 1.955 & 1.046 & 1.869 & .062 \\
\hline
\end{tabular}




\begin{tabular}{|c|c|c|c|c|c|c|c|}
\hline $\begin{array}{l}\text { Satisfaction } \\
\text { _Factor }\end{array}$ & & Factors & & & & & \\
\hline $\begin{array}{l}\text { Life } \\
\text { Satisfaction } \\
\text { _Factor }\end{array}$ & $<-$ & $\begin{array}{l}\text { Post-Depletion } \\
\text { Satisfaction }\end{array}$ & .443 & .501 & .156 & $3.204 * * *$ & .001 \\
\hline
\end{tabular}

The post-depletion satisfaction and the life satisfaction paths are as shown in $\langle$ Chart 5>. When analyzing the effect of post-depletion satisfaction on life satisfaction, the value of $\beta$ came out to be 0.443 , which indicates a significantly positive influence $(p<.001)$. This result confirmed hypothesis $\mathrm{H} 4$, which stated 'what are the effects of post-depletion satisfaction on life satisfaction?'

4.6 Intermediary Role of Post-Depletion Satisfaction Factors in the Effect of Psychological State of Illness on Life Satisfaction

Table 6. Intermediary Effects of Psychological State of IIIness on Life Satisfaction in terms of Physical Symptom, Post-Depletion Satisfaction and Self-Esteem

\begin{tabular}{|c|c|c|c|}
\hline \multicolumn{4}{|l|}{ Standardized Total Effects } \\
\hline & $\begin{array}{l}\text { Psychological } \\
\text { Illness }\end{array}$ & State & ${ }^{\text {of }}$ Post-Depletion Satisfaction \\
\hline Post-Depletion Satisfaction & $.650 * * *$ & & .000 \\
\hline Life Satisfaction Factors & $.693 * * *$ & & $.965 * * *$ \\
\hline \multicolumn{4}{|l|}{ Standardized Direct Effects } \\
\hline Post-Depletion Satisfaction & $.650 * * *$ & & .000 \\
\hline Life Satisfaction Factors & .065 & & $.965 * * *$ \\
\hline \multicolumn{4}{|l|}{ Standardized Indirect Effects } \\
\hline Post-Depletion Satisfaction & .000 & & .000 \\
\hline Life Satisfaction Factors & $.628 * * *$ & & .000 \\
\hline
\end{tabular}

Table 6 shows the intermediary effects of psychological state of illness on life satisfaction, in terms of physical symptom, post-depletion satisfaction, and self-esteem factors. The result of Bootstrap analysis about the intermediary effects of post-depletion satisfaction on the psychological state of illness on life satisfaction showed the direct effect of progressiveness to be 0.628 . There were no other variables with significant effects. This verified the hypothesis H5, which stated 'what intermediary role does postdepletion satisfaction factors play on the effects that psychological state of illness has on life satisfaction?'

\section{Discussion and Conclusion}

The effects of blood depletion for the psychological state of illness, self-esteem, and physical symptoms on life satisfaction were analyzed in this study. Based on the results, the following overall discussion points are drawn.

First, the result of factor analysis of psychological state after the illness-preventive depletion and the factor analysis of self-esteem criterion were found to have the value of 0.5 , with satisfactory level of credibility. Such result is consistent with the result of Hyun Choi's [16] study, in which the application of blood depletion on a patient with pain caused by gihyeoleochae(氣血疼滯) resulted in immediate pain relief. This means that blood depletion leads to satisfactory life without pain caused by fear of illnesses. Even though the blood depletion treatment is effective in reducing pain, it is also very important to be aware of one's diet, exercise habits, and physical state prior to the depletion.

Second, the factor analysis of satisfaction after illness-preventive depletion showed the value to be appearing from 0.5 and the satisfactory level of satisfaction. This result is 
consistent with the result of Mun-kyung Shim's [17] study, in which acupuncture and blood depletion led to quick recovery to the beginning stage of chunhengjeokmok(天行赤目). This means that blood depletion improves health conditions, and enables one to be engaged in active personal relationships and social activities. Accordingly, continuous study on the life satisfaction from depletion is considered as necessary.

Third, the result of factor analysis of the physical symptoms after illness-preventive blood depletion showed the value to be appearing from 0.5 and high value for the physical symptoms. This result is consistent with the result of Yoo-sang Baek's [10] ${ }^{\circledR}$ Hwangjaenaekyung 黃帝內經)』 which states that blood depletion immediately relieves common illnesses such as epilepsy(癎疾), gastroenteralgia(胃腸痛), and asthma (喘息). This shows that blood depletion relieves physical symptoms related to everyday pain. Accordingly, the researches on the blood depletion point (瀉血穴位), acupoint(經穴), and cautions seem necessary.

Fourth, the result of factor analysis on life satisfaction revealed the satisfactory level of credibility is .895). This result is consistent with that of Dong-hwi Kim's [18], which stated that many illnesses caused by the imbalance of the yin and yang of the aeremia and the five organs and the meridian system could be cured with blood depletion. This means that blood depletion leads to the harmony in the internal organs, and ultimately to healthier lives. Accordingly, it is necessary to develop educational programs about the methods of blood depletion.

Fifth, the result of Bootstrap analysis on the intermediary effect of the post-depletion satisfaction on life satisfaction showed that progressiveness had the direct effect of positive influence, indicated by the value of 0.628 . There were no other variables. The following are proposed based on the above results.

First, the study result shows that the psychological state of illness has a significant effect on self-esteem factors after depletion. This means that the depletion treatment increased the self-esteem regarding health and removed fear of illness. Accordingly, there is a need to develop blood depletion education programs in lifelong education centers to improve life satisfaction.

Second, the study result shows that the psychological state of illness has a significant effect on the satisfaction factors after depletion. This means that satisfaction of health condition can lead to a very satisfactory life in terms of food, housing, exercise, and relationships. Accordingly, there is a need to develop education programs in gymnasiums.

Third, the study result shows that the factors of psychological state of illness have a significant effect on the physical symptom factors. This result means that blood depletion is effective for relieving physical pains such as headaches, numbness in arms and legs, chest pain, and stomachache. Accordingly, there is a need for the establishment of natural therapy measures through blood depletion on a national health level.

Fourth, the study result shows that the post-depletion satisfaction has a significant effect on life satisfaction. This means that blood depletion leads to high level of life satisfaction. Accordingly, there is a need to operate counseling centers about the blood depletion methods in nursing homes and senior citizen centers.

Fifth, the study result shows that the post-depletion satisfaction factors play an intermediary role in the effects of the psychological state of illness on life satisfaction. This result shows that the satisfaction through blood depletion plays an intermediary role on life satisfaction.

There is a need for further study on the effect of blood depletion on natural therapy. 


\section{References}

[1] O. Yukino and K.-b. Lee, "Secrets of saengnobyeongsa", Literary publishing company, (2004), pp.18-19.

[2] C. G. Jeong, "A Study on the Revelation of the Symptom by Major Organ Specific Severe Diseases and Classification by the Science of Myung-Ri”, Department of MedicalScience Hanyang University, (2002), pp.6-7.

[3] B. C. Bae, “HwangjeNaegyeong(黃帝內經讀解)”, Seongbosa, (2000), pp.1.

[4] K. W. Lee, "HwangjeNaegyeongSoMun(黃帝內經素問 1)", Seoul, Yeogang publishing company, (1994), pp.129.

[5] D. W. Kim, "Correlation Analysis between Disease Theory in Myungri Theory and Bio Energy", The doctor's course in the Department oriental science graduate school, Kong-ju national university Journal of the Korean Society of Jungshin Science, vol.16, no.1, (2012), pp.19.

[6] F. Minoru and Y.-c. Lee, "Autonomic nervous immunotherapy”, (2008), pp.5-11.

[7] W.-c. Choi, "Cancer Treatment with Dr. Choi", Seoul; Panmidong, (2011), pp.28-36.

[8] K. W. Lee, "HwangjeNaegyeongSoMun (黃帝內經素問 2)", Yeogang publishing company, (1994), pp.134-135.

[9] G, B, Jang, “Jang’s Ryugyoung(張氏類經)”, Seongbosa. pp, 452-453, 1982.

[10] Y. S. Baik and D. H. Kim, "A Study on the Pricking Blood Therapy -HwangjeNaegyeong(黃帝內經)", Dep. of Medical Classice, Kyung Hee University, Dep. of Oriental Medical Classics, Kyungwon University, vol.1, pp.17-19.

[11] G. H. Yei, “Ever Senjucheonmi(滴天髓闡微(下)”, (2008), pp.309-315.

[12] C. G. Jeong, "A Study on the Revelation of the Symptom by Major Organ Specific Severe Diseases and Classification by the Science of Myung-Ri", Department of Medical Science Hanyang University, (2002), pp.59-60.

[13] D, W, Kim "Correlation Analysis between Disease Theory in Myungri Theory and Bio Energy“, The doctor's course in the Department oriental science graduate school, Kong-ju national university, Journal of the Korean Society of Jungshin Science, Vol, 16 No.1 pp. 47-48, 2012,

[14] D. S. Han, "A Study on Predictive Data Analytics System on History of Participants in Continuing Education Programs", Dept of Education, Dong Bang graduate University, (2013), pp.74-75.

[15] K. B. Kim1 and S. J. Cho2, "Research on the effects of Blood Depletion on the Level of Satisfaction with Psychological States of Illness, Self-Esteem and Physical Symptoms", 1 Completion of the Doctor's Course in the Department of Auto-therapy of Dongbang Cultural Graduate School, 2 Professor, Department of Education of Dongbang Cultural Graduate School, (2014), pp.4.

[16] H. Choi and S. J. Moon, "A Clinical Study on Relieving Pain of Acupuncture", Wonkang University Attached KwangJoo Oriental Medical Hospital KwangJoo City, (1981), pp.45.

[17] M. S. Sim, W. J. Hwang and G. S. Lim, "Clinical Study of Acupuncture and Venesection on Acute infectious conjunctivitis", K.O.M.S. vol.14-2, (1993), pp.137.

[18] D. H. Kim, J. C. Hyun, J. W. Chang, J. A. Lyu and Y. S. Baik, "Bloodletting Treatment of Hakjil(瘧疾)A focus on the 'Jahak(刺瘧)' chapter of Hwangjenaegyeong (黃帝內經) ·Somun (素問)”, Oriental Medical for Nuclear Science, (2011), pp.31.

[19] M. S. Chowdary and M. S. R. N. Kumar, "Effect of Nanoclay on the Mechanical properties of Polyester and S-Glass Fiber (Al)", IJAST, vol.74, (2015), pp.35-42.

[20] T. U. Ganiron Jr, "Effects of Human Hair Additives in Compressive Strength of Asphalt Cement Mixture”, IJAST, vol.67, (2014), pp.11-22. 